\title{
A unique scrotal extratesticular epidermod cyst attached to the seminal vesicles
}

\author{
Hasan Salih Sağlam, MD; ${ }^{*}$ sükrü Kumsar, MD; Osman Köse, MD;† Oztuğ Adsan, MD \\ *Sakarya University Medical Faculty, Department of Urology, Sakarya, Turkey; 'Sakarya Education and Training Hospital, Sakarya, Turkey
}

Cite as: Can Urol Assoc J 2013;7:E244-7. http://dx.doi.org/10.5489/cuai.546

\section{Abstract}

A 46-year-old man was admitted with a scrotal long standing painless mass. The workup included physical examination, alpha-fetoprotein $(\alpha \mathrm{FP})$ and beta-human chorionic gonadotropin $(\beta$-hCG) analyses, scrotal ultrasound, magnetic resonance imaging and urethrocystoscopy. Surgical exploration revealed a separate mass between the testes extending superiorly with a thin stalk. It was dissected easily to the anterior aspect of the seminal vesicles and removed from the junction to the seminal vesicles. Pathology reported an epidermoid cyst. To our knowledge this is the first case of a scrotal extratesticular epidermoid cyst attached to the seminal vesicles.

\section{Introduction}

Genital epidermoid cyst is a rare pathology and an abnormal closure of neural groove or epithelial fusion lines may be a most probable theory explaining its origin. The other theories are: (a) cutaneous tissue ectopy due to dislocation of a tissue into a neighbouring area; (b) a monolayer teratoma from germ cells; and (c) a traumatic implantation of epidermal tissue into the dermis and subcutis. The cyst is seen throughout the body in the midline from the brain to the anus. ${ }^{1,2}$ Congenital epidermoid cyst is one of the benign scrotal lesions mainly located within the testes, but may be seen in extratesticular location. ${ }^{3}$ Genital extratesticular cysts are very rare and may be encountered anywhere from the distal penile frenilum to the anal canal, having a discrete, painless lump. ${ }^{4}$ We present a unique intrascrotal extratesticular epidermoid cyst extending to the seminal vesicles.

\section{Case report}

A 46-year-old man was admitted to the urology clinic complaining of scrotal lump existing more than 10 years, enlarg- ing year by year. On physical examination a discrete, slightly firm, mobile, painless mass was palpated posteriorly to the testes (Fig. 1).Otherwise the scrotum was normal with the testes and chords. Digital rectal examination was unremarkable. Urinalysis, alpha-fetoprotein $(\alpha \mathrm{FP})$, beta-human chorionic gonadotropin $(\beta-h C G)$, lactate dehydrogenase $(\mathrm{LDH})$ and complete blood count were within normal limits ( $\alpha \mathrm{FP}$ : $2.56 \mathrm{ng} / \mathrm{mL}[<13.4] ; \beta$-hCG: <1.20 IU/L [below detectable level] and LDH: $241 \mathrm{U} / \mathrm{L}$ [240-480]). A further hormonal analysis was not required.

Ultrasound revealed a solid, hypoechoic, homogeneous and well-circumscribed lesion measuring $8.0 \times 3.3 \times 3.5 \mathrm{~cm}$ apart from the testes and extending posteriorly toward the penile root. Magnetic resonance imaging (MRI) showed a separate, oval-shaped cyst measuring $10 \times 3.4 \times 3.5 \mathrm{~cm}$, with a thin stalk traversing the pelvic floor toward the prostate in the pelvis. Additionally a right-sided renal ectopy was seen anteriorly to the fifth lumbar vertebra, on a sagittal $\mathrm{T}_{2}$-weighed image (Fig. 2). No other pathologic findings, such as lymph nodes, masses or other abnormalities located inguinally or retroperitoneally, were seen on MRI. An urethrocystoscopy was carried out and no connection to the urethelium was observed.

An operation was performed with the patient in the lithotomy position with a median raphe incision and the cyst was dissected easily toward the true pelvis. The stalk of the cyst was tapering and traversed the pelvic floor and attached to the seminal vesicles in the midline (Fig. 3). The cyst was removed from the junction to the seminal vesicles and sent to pathology. Pathologic examination revealed a thin $(1 \mathrm{~mm})$ and intact wall lined by stratified squamous epithelium containing a cheesy material, with diagnosis of epidermoid cyst (Fig. 4). The patient was well at the 9-month postoperative follow-up.

\section{Discussion}

Epidermoid cysts are divided into two types: congenital and acquired. ${ }^{5}$ Although there are many theories about histo- 


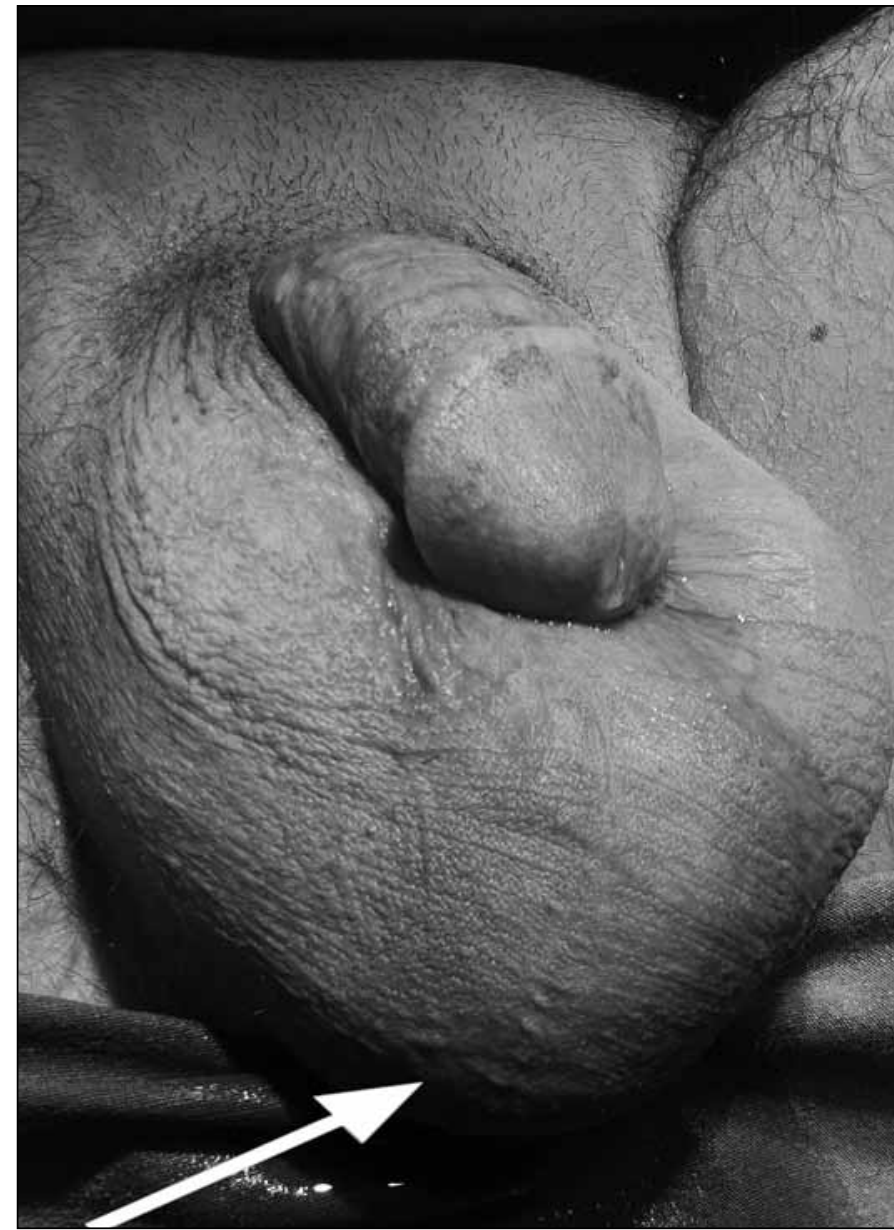

Fig. 1. Arrow shows the lump.

genesis, such as teratoma and metaplasia, the most likely explanation of epidermoid cysts throughout the body is an early intrauterine abnormal closure of neural groove or epithelial fusion lines. ${ }^{1,2,6}$ It has been reported in any place from the cranium to the anus in midline. ${ }^{2,4}$ Epidermoid cyst is one of the benign lesions in the scrotum, and most published cases are located within the testes; this makes it a challenge to the patient and surgeon in terms of preserving the organ. Scrotal and extratesticular epidermoid cysts, as was the case in our patient, are very rare; the number of cases published in the English literature is less than 10., ${ }^{1,3},-9$

In our case scrotal epidermoid cyst was also attached to the anterior aspect of the seminal vesicles in the midline. There is only one reported case of a dermoid cyst arising from the posterior aspect of the prostate and seminal vesicles, but the cyst was in the pelvis masquerading as a full bladder. ${ }^{9}$ Three other case reports in the literature exhibited scrotal extratesticular epidermoid cysts extending in to the pelvis, but no attachments to the seminal vesicles were mentioned. ${ }^{3,8}$ To our knowledge, this is the first case in the English literature.

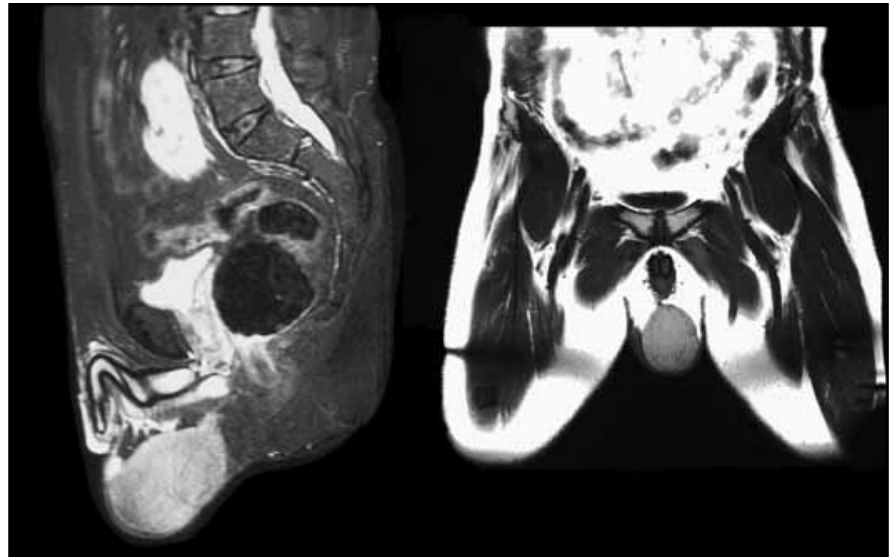

Fig. 2. Sagittal and coronal planes on magnetic resonance imaging.

Extratesticular epidermoid cysts, if they are palpable, cannot be hidden as is the case with cysts in intratesticular locations. Therefore, these extratesticular epidermoid cysts can be diagnosed earlier, but some patients have the lesion for years before being admitted to hospital. ${ }^{1,7}$ This was the case in our patient.

Tumour markers are of value as an initial workup for malignant lesions. ${ }^{10}$ We studied $\alpha \mathrm{FP}, \beta$-hCG and LDH in addition to routine biochemical tests, but they were within normal limits. No additional hormonal analysis was done due to the general status of the patient on admission. Certainly, malignancy could not be excluded on the basis of tumour markers, however, if the tests are within normal limits, testis-sparing surgery, a highly desirable option for young patients, may be done with testicular cysts. ${ }^{11}$ Our case was an extratesticular cyst, so we did not hesitate to remove the lesion completely.

For diagnosis, scrotal ultrasound is usually the first and most important way to explore the scrotal content. It can differentiate the location of lesions as intratesticular or extratesticular and the content of the lesions as solid or cystic. ${ }^{1}$ For the intratesticular lesions, the most famous ultrasound pattern is "onion skin" appearance formed by the enlarging cyst within the testis and the surrounding parenchyme forced outward. ${ }^{6}$ For extratesticular lesions, a well-circumscribed mass can be seen, but the echotexture may be hypoechoic or hyperechoic depending on its content. ${ }^{7}$ Therefore, ultrasound findings may be confusing. ${ }^{1}$ In our patient, scrotal ultrasound showed a hypoechoic, separate, extratesticular, well-defined cyst extending posteriorly to the perineum.

On MRI, testicular epidermoid cysts have been described as having "bull's-eye" appearance corresponding to multiple layers of keratinous desquamation. For extratesticular cysts MRI shows a thin walled mass with keratinous debris, having low signal on T1 weighed images and high signal on T2 images as in testicular lesions. The most extra testicular epidermoid cysts appear as hypoechoic masses contain- 


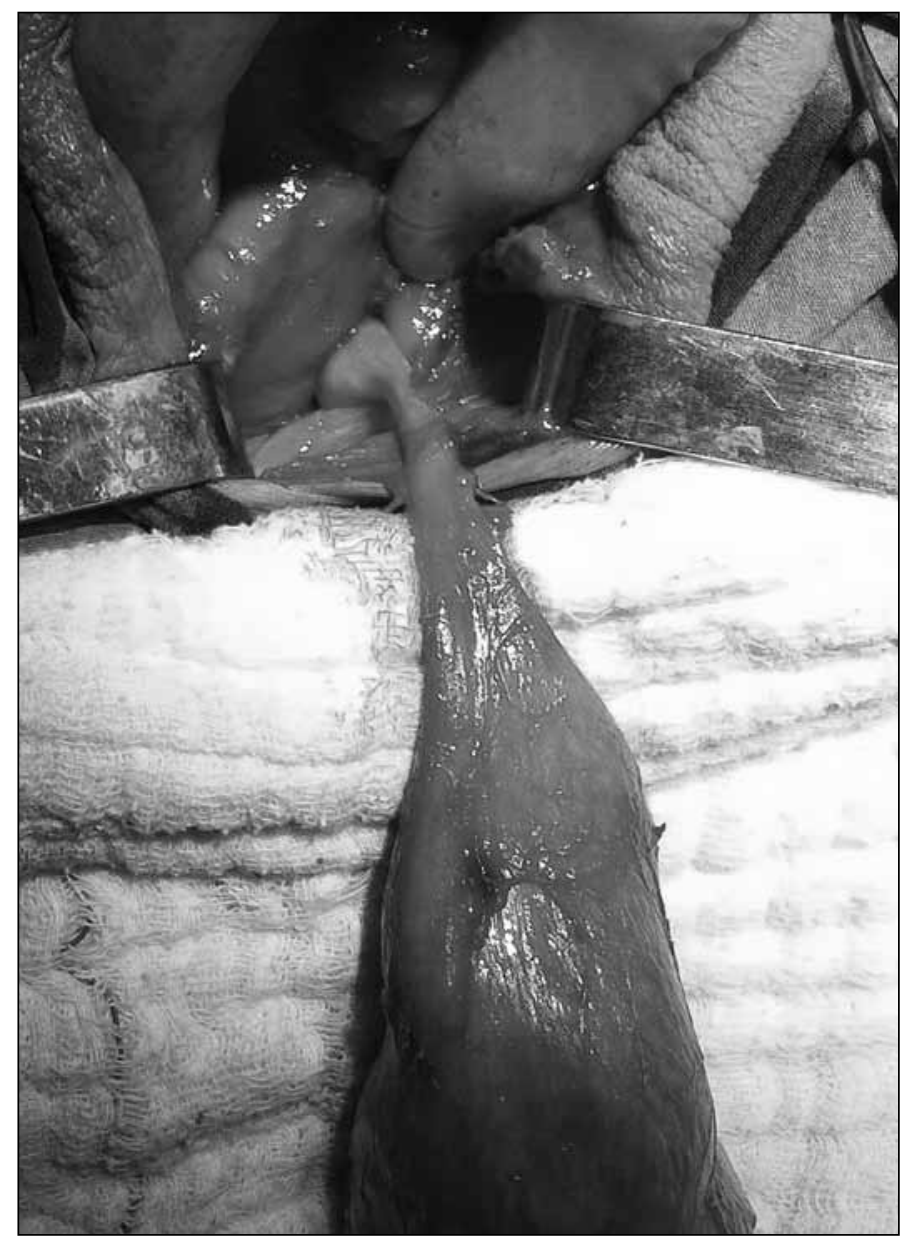

Fig. 3. The stalk of the cyst attached to the seminal vesicles.

ing variable echogenic foci. ${ }^{1,6}$ When US gives confusing information due to altering echogenicity, MRI could play a complementary role in such cases. ${ }^{11,12}$ In our case MRI was the most useful tool for differentiating the scrotal structures clearly so providing an anatomical road map for surgery. Although seminal vesicle attachment could not be exhibited exactly but intrapelvic extension has been demonstrated.

Computed tomography (CT), due to a non-neglectable radiation dose for scrotal lesions, may increase the risk of future radiation-induced secondary cancer. Therefore, it is best to substitute CT with MRI. There is evidence that the diagnostic value of MRI is at least comparable to current multi-slice CT. ${ }^{13}$ Meanwhile, MRI is effective in depicting intra- and extratesticular masses; it can show various tissue types, including cysts or fluid, solid masses, fat and fibrosis. Also, after administering a gadolinium-based contrast material, it was shown that an MRI assessed the vascularity of testicular lesions more accurately than a colour Doppler ultrasound. ${ }^{14}$

While the management of the lesion for testicular cysts seems controversial, ${ }^{6}$ complete surgical removal of the extra-

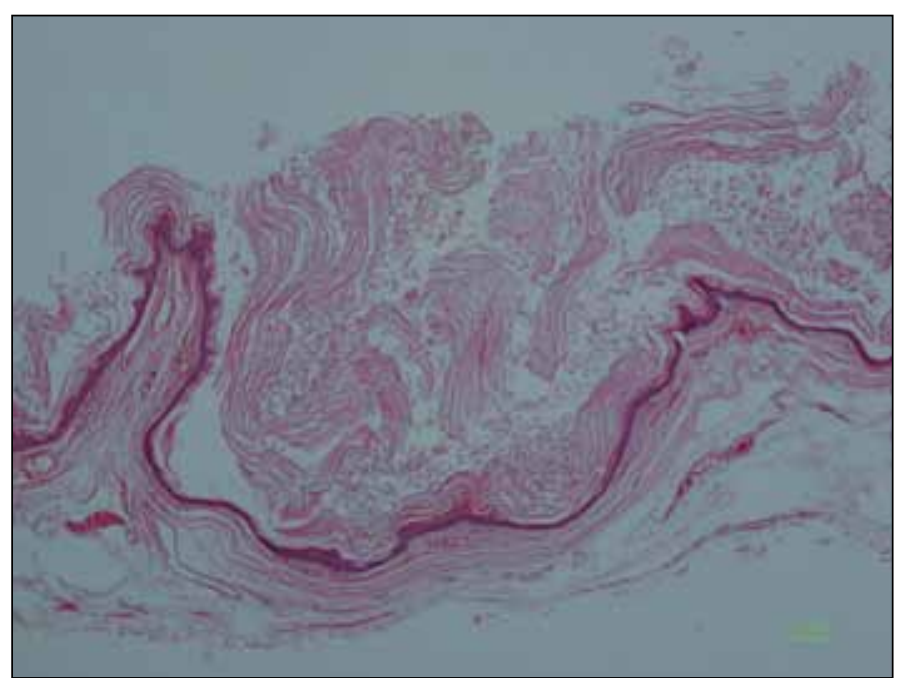

Fig. 4. Histological slide of epidermoid cyst showing squamous epithelium surrounding laminated keratin layers (Hematoxylin and eosin stain).

testicular cyst was advocated in our patient because the imaging features that are characteristic of epidermoid cysts did not exclude malignant neoplasms, such as liposarcoma, fibrosarcoma and metastatic disease. ${ }^{2}$ Additionally, in cases of extratesticular cysts, the testes are intact, therefore organsparing surgery is not needed (this is especially important in young patients). In our patient, we removed the lesion completely. Nine months postoperatively, the patient was examined and no problem was detected in terms of the lesion.

\section{Conclusion}

If ultrasound and MRI confirm intrascrotal-extratesticular epidermoid cyst and if the serum levels of $\alpha \mathrm{FP}, \beta-\mathrm{HCG}$ and LDH are normal, then the cyst should be excised completely and no further treatment should be necessary.

Competing interests: None declared.

This paper has been peer-reviewed.

\section{References}

1. Lee SJ, Lee JH, Jeon SH, et al. Multiple Epidermoid Cysts Arising from the Extratesticular Scrotal, Spermatic Cord and Perineal Area. KJU 2010;51:505-7. http://dx.doi.org/10.4111/kju.2010.51.7.505

2. Pear BL. Epidermoid and dermoid sequestration cysts. AJR Am J Roentgenol 1970;1 10:148-54. http:// dx.doi.org/10.2214/aj.110.1.148

3. Huang A, Palmer $L S$, Levitt SB. Epidermoid cyst of the scrotum extending into the true pelvis. Urology 1999;54:561. http://dx.doi.org/10.1016/S0090-4295(99)00197-1

4. Suwa $M$, Takeda $M$, Bilim W, et al. Epidermoid cyst of the penis: A case report and review of the literature. Int J Urol 2000;7:431-3. http://dx.doi.org/10.1046/i.1442-2042.2000.00219.x

5. Pear BL. Epidermoid and dermoid sequestration cysts. Am J Roentgenol Radium Ther Nucl Med 1970;110:148-55. http://dx.doi.org/10.2214/air.110.1.148 
6. Malvica RP. Epidermoid cyst of the testicle: an unusual sonographic finding. AJR Am J Roentgenol 1993;160:1047-8. http://dx.doi.org/10.2214/air.160.5.8470573

7. Matthew D, Reed CM, Dykes TM, et al. Epidermoid Inclusion Cyst of the Scrotum. Appl Radiol, 2008; 37 (6). http://www.medscape.com/viewarticle/576239. Accessed March 27, 2013.

8. Göktas $S, 0 z$, ök Y, Tahmaz L, et al. Extratesticular epidermoid cyst with extension into the pelvis. Scand J Urol Nephrol 1997;31:109-10. http://dx.doi.org/10.3109/00365599709070314

9. Van Gelderen WF, al-Hindawi M, Archibald CG, et al. Radiological imaging of a massive dermoid in the male pelvis. Austral Radiol 1995;39:408-10. http://dx.doi.org/10.1111/i.1440-1673.1995.tb00324.x

10. Loya AG, Said JW, Grant EG. Epidermoid Cyst of the Testis: Radiologic-Pathologic Correlation. Radiographics 2004;24:S243-6.

11. Kao HW, Wu CJ, Cheng MF, et al. Extratesticular epidermoid cyst mimicking enlarged testis. Ir J Med Sci 2011;180:593-5. http://dx.doi.org/10.1007/s11845-008-0264-6
12. Tsili AC, Tsampoulas C, Giannakopoulos $X$, et al. MRI in the Histologic Characterization of Testicular Neoplasms. AJR Am J Roentgenol 2007;189:W331-7. http://dx.doi.org/10.2214/AJR.07.2267

13. Hansen J, Jurik AG. Diagnostic value of multislice computed tomography and magnetic resonance imaging in the diagnosis of retroperitoneal spread of testicular cancer: a literature review. Acta Radiol 2009;50:106470. http://dx.doi.org/10.3109/02841850903220371

14. Cassidy FH, Ishioka KM, McMahon CJ, et al. MR Imaging of Scrotal Tumors and Pseudotumors. Radiographics 2010;30:665-83. http://dx.doi.org/10.1148/rg.303095049

Correspondence: Dr. Hasan Salih Sağlam, Sakarya University Medical Faculty, Department of Urology, Sakarya, Uroloii Kliniği, Sakarya, Turkey; fax:+90 264275 91 92; hasanss@hotmail.com 